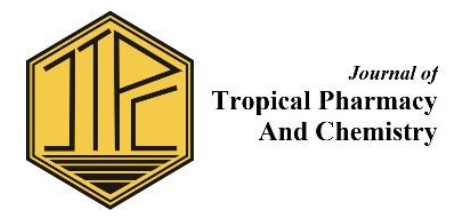

\title{
AKTIVITAS ANTIOKSIDAN SENYAWA KUMARIN TER-O-GERANILASI DARI AKAR Limonia acidissima $\mathbf{L}$.
}

\author{
Tjitjik Srie Tjahjandarie $^{1^{*}}$, Ratih Dewi Saputri ${ }^{1}$, Mulyadi Tanjung ${ }^{1}$ \\ ${ }^{1}$ Natural Products Chemistry Research Group, Organic Chemistry Division, \\ Department of Chemistry, Faculty of Science and Technology, Universitas Airlangga, Surabaya 60115, \\ Indonesia \\ *Corresponding author email: tjitjiktjahjandarie@fst.unair.ac.id
}

\begin{abstract}
Five $O$-geranylated coumarins namely as auraptene (1), 7-((2' E,6' $E)-5^{\prime}$-hydroxy-3', $7^{\prime}$-dimethylocta-2',6'dienyloxy)coumarin (2), 7-(2'E,5'E)-7'-hydroxy-3', $7^{\prime}$-dimethylocta-2', 5'-dienyloxy) coumarin (3), 6methoxy-7-oxygeranylcoumarin (4), and 8-oxygeranylpsoralen (5) were isolated from the roots of Limonia accidissima L. Their structures were determined based on spectroscopic data such as UV, IR, MS and NMR. Compounds 1-5 were evaluated for their radical scavenging against 2,2-diphenyl-1-picrylhydrazyl (DPPH), showing their $\mathrm{IC}_{50}$ were $462 ; 13 ; 260 ; 210$ and $234 \mu \mathrm{g} / \mathrm{ml}$, respectively.
\end{abstract}

Keywords: Limonia accidissima L., $O$-geranylated coumarins, antioxidant activity, DPPH

\begin{abstract}
ABSTRAK
Lima senyawa kumarin ter- $O$-geranilasi yakni aurapten $(\mathbf{1})$, 7-(2' $\left.E, 6^{\prime} E\right)-5^{\prime}$-hidroksi-3', $7^{\prime}$-dimetilokta-2',6'dieniloksi)kumarin (2), 7-(2'E,5'E)-7'- hidroksi -3', 7'- dimetilokta-2', 5'-dieniloksi) kumarin (3), 6-metoksi7-oksigeranilkumarin (4), dan 8-oksi-geranilpsoralen (5) telah diisolasi dari akar Limonia accidissima L. Struktur senyawa kumarin tergeranilasi ditetapkan berdasarkan analisis spektroskopi UV, IR, MS dan NMR. Uji aktivitas antioksidan senyawa $\mathbf{1 - 5}$ terhadap radikal DPPH memperlihatkan $\mathrm{IC}_{50} 462 ; 13 ; 260 ; 210$ dan $234 \mu \mathrm{g} / \mathrm{ml}$.
\end{abstract}

Kata kunci: Limonia accidissima L., kumarin ter-O-geranilasi, aktivitas antioksidan, DPPH

Submitted on: 7 November 2017

Accepted on:21 Desember 2017

DOI: https://doi.org/10.25026/jtpc.v4i2.143

\section{PENDAHULUAN}

Limonia accidissima L. (sinonim: Feronia limonia) dikenal dengan nama kawista dan merupakan salah satu spesies famili jeruk-jerukan ( Rutaceae). Secara tradisional, tumbuhan ini dimanfaatkan masyarakat sebagai obat seperti diare, disentri, tumor, asma, luka, lemah jantung, hepatitis dan buahnya dapat dikomsumsi [1]. Pemanfaatan tumbuhan ini dalam pengobatan tradisional tentunya berhubungan dengan senyawa aktif yang terdapat dalam tumbuhan Limonia acidissima $\mathrm{L}$.

Kumarin merupakan jenis senyawa fenolik utama yang ditemukan pada tumbuhan Limonia acidissima L. [2]. Ciri khas senyawa kumarin pada tumbuhan ini mempunyai substituen isoprenil $\left(\mathrm{C}_{5}\right)$ dan geranil $\left(\mathrm{C}_{10}\right)$ yang 
terikat pada inti aromatik kumarin. Berdasarkan substituen tersebut maka senyawa kumarin Limonia acidissima L. terdiri dari jenis kumarin terisoprenilasi, kumarin ter- $O$-isoprenilasi, furanokumarin, piranokumarin, dan kumarin ter- $O$-geranilasi. Senyawa kumarin Limonia acidissima L. memperlihatkan aktivitas antimalaria dan antioksidan [3].

Kajian fitokimia senyawa kumarin ter-O-geranilasi dari Limonia acidissima L. sampai saat ini belum ada laporan penelitian yang berasal dari Indonesia. Pada kesempatan kali ini akan dilaporkan penemuan lima senyawa kumarin ter- $O$ geranilasi, yakni aurapten (1), 7((2'E,6'E)-5'-hidroksi-3',7'-dimetilokta2',6'-dieniloksi)kumarin (2), 7-(2' $\left.E, 5^{\prime} E\right)$ 7'- hidroksi -3',7'- dimetilokta-2',5'dieniloksi) kumarin (3), 6-metoksi-7oksigeranilkumarin (4), dan 8-oksigeranilpsoralen (5) dari akar Limonia acidissima L.. Selain itu juga akan dilaporkan aktivitas antioksidan kelima senyawa kumarin terhadap DPPH (2,2diphenyl-1-picrylhydrazyl).

\section{METODE PENELITIAN}

\section{Prosedur Umum}

Kromatografi cair vakum $(\mathrm{KCV})$

dan kromatografi kolom tekan menggunakan silika gel $60 \quad \mathrm{GF}_{254}$ (Merck), kromatografi radial menggunakan silika gel $60 \mathrm{PF}_{254}$ (Merck) dan kromatografi lapis tipis (KLT) menggunakan plat KLT silika gel 60 $\mathrm{GF}_{254} 0.25 \mathrm{~mm}$ (Merck). Spektrum UV ditetapkan dengan spektrofotometer UVVis Shimadzu 1800. Spektrum IR ditentukan dengan spektrofotometer IR Perkin Elmer. Spektrum massa ditentukan dengan spektrometer HR-ESIMS merck Waters LCT XE ESI. Spektrum NMR ditentukan dengan spektrometer NMR JEOL ECA 400 yang beroperasi pada $400 \mathrm{MHz}\left({ }^{1} \mathrm{H}-\mathrm{NMR}\right)$ dan $100 \mathrm{MHz} \quad\left({ }^{13} \mathrm{C}-\mathrm{NMR}\right) . \mathrm{Uji}$ aktivitas antioksidan terhadap radikal DPPH ditentukan menggunakan metode spektrometri.

\section{Bahan tumbuhan}

Bahan tumbuhan berupa akar Limonia acidissima L. diperoleh dari Desa Panjunan, Kecamatan Palang, Kabupaten Tuban, JawaTimur. Spesimen tumbuhan diidentifikasi di Herbarium Bogorienses, Lembaga Ilmu Pengetahuan Indonesia (LIPI) Biologi, Cibinong, Bogor, Jawa Barat.

\section{Ekstraksi dan isolasi kumarin ter-O- geranilasi}

Ekstraksi akar Limonia acidissima L. sebanyak 4,0 kg dengan maserasi menggunakan metanol pada suhu kamar. Ekstrak metanol yang diperoleh dipekatkan dengan alat penguap bertekanan rendah sehingga diperoleh ekstrak kental metanol (123.3g). Ekstrak metanol selanjutnya dipartisi dengan $n$ heksana menghasilkan dua lapisan, ekstrak $n$-heksana dan ekstrak metanol. Ekstrak metanol selanjutnya ditambahkan asam sitrat 5\% sampai $\mathrm{pH} \mathrm{3-4} \mathrm{kemudian}$ dipartisi dengan etil asetat menghasilkan dua lapisan, ekstrak etil asetat dan ekstrak metanol asam. Pemisahan ekstrak etil asetat (35 g) dengan KCV menggunakan campuran eluen $n$-heksana:etil asetat (9:1, 8:2, 1:1 dan 3:7) menghasilkan empat fraksi utama A-D. Pemisahan fraksi B (563 mg) menggunakan kromatografi kolom tekan dengan campuran eluen $n$-heksana:etil asetat (9:1 sampai 7:3) menghasilkan empat sub fraksi $B_{1}-B_{4}$. Pemurnian subfraksi $B_{1}$ $(152,4 \mathrm{mg})$ menggunakan kromatografi radial dengan campuran eluen nheksana:etil asetat (9:1 sampai 7:3) menghasilkan senyawa aurapten (1) sebanyak $18 \mathrm{mg}$ dan senyawa 8-oksi- 
geranilpsoralen (5) sebanyak $12 \mathrm{mg}$. Pemisahan fraksi C (1,2 g) dengan kromatografi kolom tekan dengan eluen yang sama dengan pemurnian fraksi $\mathrm{B}$ menghasilkan empat subfraksi $\mathrm{C}_{1}-\mathrm{C}_{4}$. Pemurnian subfraksi $\mathrm{C}_{1} \quad(152,4 \quad \mathrm{mg})$ menggunakan kromatografi radial dengan campuran eluen $n$-heksana: $\mathrm{CHCl}_{3} \quad(9: 1$ sampai 3:7) menghasilkan senyawa 7((2'E,6'E)-5' 'hidroksi-3', 7'-dimetilokta2',6'-dieniloksi) kumarin (2) sebanyak 8 $\mathrm{mg}, \quad 7-\left(2^{\prime} E, 5^{\prime} E\right)-7^{\prime}-\mathrm{hidroksi} \quad-3^{\prime}, 7^{\prime}-$ dimetilokta-2',5'- dieniloksi) kumarin (3) sebanyak $6 \mathrm{mg}$ dan 6-metoksi-7oksigeranilkumarin (4) sebanyak $12 \mathrm{mg}$.

Aurapten (1), berwujud padatan kuning, titik leleh t.l. $62-64^{\circ} \mathrm{C}$. Spektrum UV (MeOH) $\lambda_{\text {maks }}$ nm (log $\left.\varepsilon\right): 224(3,21)$, $289(3,08)$ dan $324(3,43) \mathrm{nm}$. Spektrum IR (Kbr) v $v_{\text {maks }}\left(\mathrm{cm}^{-1}\right): 3083 ; 3055(\mathrm{C}-\mathrm{H}$ aromatik), 2974; 2896; $2879 \quad$ (C-H alifatik), $1730(\mathrm{C}=\mathrm{O} \alpha$-piran $), 1612 ; 1452$ $(\mathrm{C}=\mathrm{C}$ aromatik), 1236; 1203 (C-O-C eter). HRESIMS $m / z,[\mathrm{M}+\mathrm{H}]^{+} 299,1650$ (perhitungan untuk rumus molekul $\left.\mathrm{C}_{19} \mathrm{H}_{23} \mathrm{O}_{3}, 299,1647\right)$. Spektrum ${ }^{1} \mathrm{H}$ dan ${ }^{13} \mathrm{C}$ NMR $\left(\mathrm{CDCl}_{3}\right)$ dapat dilihat pada Tabel-1.

\section{7-((2'E,6'E)-5'-Hidroksi-3',7'-} dimetilokta-2',6'-dieniloksi) kumarin (2) berwujud padatan kuning, UV $(\mathrm{MeOH})$ $\lambda_{\text {maks }} \mathrm{nm}(\log \varepsilon): 224(3,21), 289(3,08)$ dan $324(3,43) \mathrm{nm}$. Spektrum ${ }^{1} \mathrm{H}$ dan ${ }^{13} \mathrm{C}$ NMR $\left(\mathrm{CDCl}_{3}\right)$ dapat dilihat pada Tabel-2.

7-(2'E,5'E)-7'- Hidroksi -3', 7'dimetilokta-2',5'- dieniloksi) kumarin (3) berwujud padatan kuning, UV $(\mathrm{MeOH})$ $\lambda_{\text {maks }} \mathrm{nm}(\log \varepsilon): 224(3,21), 289(3,08)$ dan $324(3,43) \mathrm{nm}$. Spektrum ${ }^{1} \mathrm{H}$ dan ${ }^{13} \mathrm{C}$ NMR $\left(\mathrm{CDCl}_{3}\right)$ dapat dilihat pada Tabel-3.

6-Metoksi-7-oksigeranilkumarin (4) berwujud padatan kuning, UV $(\mathrm{MeOH})$ $\lambda_{\text {maks }} \mathrm{nm}(\log \varepsilon): 224(3,21), 289(3,08)$ dan $324(3,43) \mathrm{nm}$. Spektrum ${ }^{1} \mathrm{H}$ dan ${ }^{13} \mathrm{C}$ NMR $\left(\mathrm{CDCl}_{3}\right)$ dapat dilihat pada Tabel-4.

8-Oksi-geranilpsoralen berwujud padatan kuning, UV $(\mathrm{MeOH})$ $\lambda_{\text {maks }} \mathrm{nm}(\log \varepsilon): 224(3,21), 289(3,08)$ dan $324(3,43) \mathrm{nm}$. Spektrum ${ }^{1} \mathrm{H}$ dan ${ }^{13} \mathrm{C}$ NMR $\left(\mathrm{CDCl}_{3}\right)$ dapat dilihat pada Tabel-5.

\section{Uji aktivitas antioksidan terhadap radikal DPPH}

\begin{tabular}{lccr}
\multicolumn{2}{c}{ Penentuan uji } & aktivitas \\
antioksidan & senyawa & $\mathbf{1 - 5}$ & terhadap \\
radikal & DPPH & \multicolumn{2}{c}{$(2,2-$ difenil-1- } \\
pikrihidrazil) & menggunakan & analisis \\
spektrometer & UV pada panjang
\end{tabular}
gelombang $\lambda 517 \mathrm{~nm}$ [4], [5], [6]. Persentase konsentrasidaya hambat senyawa 1-5 terhadap radikal DPPH dihitung menggunakan persamaan:

$\%$ Inhibisi senyawa $=\left(A_{o}-A_{s} l\right.$ $\mathrm{A}_{\text {o) }} \times 100$.

Dimana $\quad \mathrm{A}_{\mathrm{o}}$ merupakan absorbansi DPPH dand $\mathrm{A}_{\mathrm{s}}$ merupakan absorbansi campuran senyawa aktif dan DPPH. Kontrol positif uji aktivitas antioksidan menggunakan asam askorbat [7-9].

\section{HASIL DAN PEMBAHASAN}

Lima senyawa kumarin ter- $O$ geranilasi, yakni aurapten (1), 7((2'E,6' $E)$-5' -hidroksi-3', 7'-dimetilokta2',6'-dieniloksi)kumarin (2), 7-(2'E,5'E)7'- hidroksi -3', 7' - dimetilokta-2', 5'dieniloksi) kumarin (3), 6-metoksi-7oksigeranilkumarin (4), dan 8-oksigeranilpsoralen (5) telah berhasil diisolasi dari ekstrak etil asetat akar Limonia acidissima $\mathrm{L}$.

Aurapten (1) berwujud padatan kuning muda memperlihatkan ion kuasimolekul positif $[\mathrm{M}+\mathrm{H}]^{+}$pada $\mathrm{m} / \mathrm{z}$ 299,1650 yang sesuai dengan rumus molekul $\mathrm{C}_{19} \mathrm{H}_{23} \mathrm{O}_{3}$ berdasarkan hasil pengukuran HR-ESI-MS. Spektrum ${ }^{1} \mathrm{H}$ NMR (400 MHz) senyawa 1 dalam $\mathrm{CDCl}_{3}$ memperlihatkan tiga sinyal proton aromatik dari sistem $\mathrm{ABX}$ pada pergeseran kimia $\delta_{\mathrm{H}} 7,34(d, J=8,6 \mathrm{~Hz})$; $6,83(d d, J=8,6 ; 2,4 \mathrm{~Hz})$; dan 6,80 ppm $(d, J=2,4 \mathrm{~Hz})$ dan sepasang sinyal 
doublet cis-vinilik $(J=9,6 \mathrm{~Hz})$ pada $\delta_{\mathrm{H}}$ 7,61 dan 6,23 ppm yang khas untuk senyawa kumarin di posisi $\mathrm{H}-4$ dan $\mathrm{H}-3$ yang khas untuk senyawa kumarin monosubstisi di C-7. Sinyal proton sisa pada spektrum ${ }^{1} \mathrm{H}-\mathrm{NMR}$ memperlihatkan adanya dua sinyal proton metin pada $\delta_{\mathrm{H}}$ $5,45 \mathrm{ppm}(t, J=6,6 \mathrm{~Hz}), 5,06 \mathrm{ppm}(t, J=$ $6,6 \mathrm{~Hz})$, tiga sinyal proton metilen pada $\delta_{\mathrm{H}} 4,58 \mathrm{ppm}(d, J=6,5 \mathrm{~Hz}) ; 2,12 \mathrm{ppm}$ $(m), 2,10(m)$, serta tiga sinyal proton singlet dari metil pada pergeseran kimia $\delta_{\mathrm{H}} 1,75 ; 1,65 ;$ dan $1,59 \mathrm{ppm}$ memberi indikasi bahwa senyawa $\mathbf{1}$ mempunyai substituen geranil terikat di C-7. Spektrum ${ }^{13} \mathrm{C}-\mathrm{NMR}$ (percobaan APT, $100 \mathrm{MHz}$ ) senyawa 1 memperlihatkan 19 sinyal atom karbon yang terpisah secara sempurna, konsisten untuk struktur senyawa kumarin ter- $O$-geranilasi. Sinyal karbon pada $\delta_{\mathrm{C}}$ 65,6 ppm merupakan sinyal karbon eter dan memberi konfirmasi senyawa 1 mempunyai substituen ter $O$-geranilasi di C-7.<smiles>COc1cc2ccc(=O)oc2cc1OCC=C(C)CCC=C(C)C</smiles>

Gambar 1. Struktur kumarin ter-O-geranilasi hasil isolasi

Berdasarkan pengukuran $\mathrm{HMBC}$ (Tabel-1), sinyal proton metilen pada $\delta_{\mathrm{H}}$ 4,58 (H-1') memperlihatkan korelasi dengan satu sinyal karbon oksiaril pada
$\delta_{\mathrm{C}} 162,2(\mathrm{C}-7)$, satu sinyal karbon metin pada $\delta_{\mathrm{C}} 118,5$ (C-2') dan satu sinyal karbon kuarterner pada $\delta_{\mathrm{C}} 142,5$ (C-3'). Berdasarkan data tersebut maka 
disimpulkan bahwa senyawa $\mathbf{1}$ adalah senyawa aurapten [3]. Korelasi antara sinyal proton dengan sinyal karbon dalam dua atau tiga ikatan pada spektrum HMBC yang utama untuk mendukung struktur senyawa aurapten hasil isolasi dapat dilihat pada Tabel-1.

7-(2'E,6' $E)-5^{\prime}$-Hidroksi-3',7'-

dimetilokta-2',6'-dieniloksi) kumarin (2) berwujud padatan kuning. Spektrum ${ }^{1} \mathrm{H}-$ NMR senyawa 2 (Tabel-2) mirip dengan senyawa $\mathbf{1}$ yakni adanya sistem ABX dan sepasang sinyal doublet cis vinilik. Perbedaan utama pada spektrum ${ }^{1} \mathrm{H}$ NMR senyawa 2 memperlihatkan tiga sinyal proton metin pada $\delta_{\mathrm{H}} 5,55 ; 5,16$; 4,51 , dua sinyal proton metilen pada $\delta_{\mathrm{H}}$ 4,$59 ; 2,25$, dan tiga sinyal proton singlet dari metil pada pergeseran kimia $\delta_{\mathrm{H}} 1,80$; 1,69; dan 1,67 ppm. Spektrum ${ }^{13} \mathrm{C}-\mathrm{NMR}$ senyawa 2 memperlihatkan 19 sinyal karbon yang terpisah secara sempurna. Korelasi ${ }^{1} \mathrm{H}-{ }^{13} \mathrm{C}$ dalam dua atau tiga ikatan pada spektrum HMBC (Tabel-2), dua sinyal proton metil pada $\delta_{\mathrm{H}} 1,69(\mathrm{H}-$ 8) dan 1,67 (H-9) masing-masingnya memperlihatkan korelasi dengan satu sinyal karbon metin pada $\delta_{\mathrm{C}} 127,2$ (C-6') dan satu sinyal karbon kuarterner pada $\delta_{\mathrm{C}} 135,5$ (C-7'). Sinyal proton hidroksi pada $\delta_{\mathrm{H}} 4.51 \quad(\mathrm{H}-5$ ') memperlihatkan korelasi dengan $\delta_{\mathrm{C}} \quad 135,5$ (C-7'). Berdasarkan data tersebut maka disimpulkan bahwa senyawa 2 adalah senyawa 7-(2'E,6'E)-5'-hidroksi-3',7'dimetilokta-2',6'-dieniloksi) kumarin [10]. Korelasi sinyal proton dengan sinyal karbon pada spektrum HMBC yang untuk mendukung struktur senyawa 2 dapat dilihat pada Tabel-2.

Spektrum ${ }^{1} \mathrm{H}-\mathrm{NMR}$ senyawa 7 (2'E, 5' $E)-7^{\prime}$ '-hidroksi -3',7'- dimetilokta2',5'-dieniloksi) kumarin (3) mempunyai kerangka kumarin yang sama dengan senyawa $\mathbf{1}$ dan $\mathbf{2}$ yakni adanya sistem ABX dan sepasang proton cis vinilik (Tabel-3). Perbedaan yang prinsip, spektrum ${ }^{1} \mathrm{H}-\mathrm{NMR}$ senyawa $\mathbf{3}$ dengan senyawa $\mathbf{1}$ dan $\mathbf{2}$ adalah pada sinyal proton ter- $O$-geranilasi di C-7. Spektrum ${ }^{13} \mathrm{C}-\mathrm{NMR}$ senyawa $\mathbf{3}$ mempunyai 18 sinyal karbon yang mewakili 19 atom karbon. Spektrum HMBC senyawa 3, sinyal singlet proton metil pada $\delta_{\mathrm{H}} 1,32$ (H-8'/H9') memperlihatkan korelasi dengan dua sinyal karbon metin alkena pada $\delta_{\mathrm{C}} 140.4$ (C-6') dan sinyal karbon alkohol $\delta_{\mathrm{C}} 70,7$ (C-7'). Sinyal proton metilen pada pergeseran kimia $\delta_{\mathrm{H}} 2,78$ (H-4') memperlihatkan korelasi dengan tiga sinyal karbon metin yakni pada $\delta_{\mathrm{C}}$ 140,4 (C-6'), $\delta_{\mathrm{C}} 123,8$ (C-5'), 119,2 (C2 '), satu sinyal karbon metil pada 16,8 (C-10'). Berdasarkan spektrum HMBC maka disimpulkan bahwa senyawa 3 adalah senyawa $7-\left(2^{\prime} E, 5^{\prime} E\right)-7^{\prime}$-hidroksi 3',7'- dimetilokta-2',5'-dieniloksi) kumarin [11]. Spektrum HMBC yang mendukung struktur senyawa $\mathbf{3}$ dapat dilihat pada Tabel-3.

6-Metoksi-7-oksigeranilkumarin

(4) berwujud padatan kuning muda. Spektrum ${ }^{1} \mathrm{H}-\mathrm{NMR}$ senyawa 4 memperlihatkan dua sinyal singlet proton aromatik pada $\delta_{\mathrm{H}} 6,85$ dan $6,83 \mathrm{ppm}$ dan sepasang sinyal doublet cis-vinilik $(J=$ 9,5 Hz) pada $\delta_{\mathrm{H}}$ 7,62 dan 6,27 ppm yang khas untuk senyawa kumarin disubstitusi. Sinyal proton senyawa $\mathbf{4}$ memperlihatkan adanya sinyal proton geranil dan metoksi. Spektrum ${ }^{13} \mathrm{C}-\mathrm{NMR}$ senyawa 4 memperlihatkan 20 sinyal atom karbon yang terpisah secara sempurna. Spektrum HMBC (Tabel-4) memperlihatkan adanya korelasi antara sinyal proton metilen pada $\delta_{\mathrm{H}} 4,69(\mathrm{H}-1$ ') memperlihatkan korelasi dengan satu sinyal karbon oksiaril pada $\delta_{\mathrm{C}} 152.0$ (C-7), satu sinyal karbon metin pada $\delta_{\mathrm{C}} 118,3$ (C-2') dan satu sinyal karbon kuarterner pada $\delta_{\mathrm{C}} 142.1$ (C-3') yang menunjukkan $O$-geranil terikat di C7. Sinyal singlet proton aromatik pada $\delta_{\mathrm{H}}$ 6,83 (H-8) memperlihatkan korelasi dengan satu sinyal karbon oksiarin pada 
$\delta_{\mathrm{C}} 146.6(\mathrm{C}-6)$ dan satu sinyal karbon kuarterner pada $\delta_{\mathrm{C}} \quad 111.2 \quad(\mathrm{C}-10)$ sedangkan sinyal proton metoksi berkorelasi dengan sinyal karbon oksiarin pada $\delta_{\mathrm{C}} 146.6(\mathrm{C}-6)$. Analisis spektrum HMBC tersebut maka disimpulkan bahwa senyawa 4 adalah senyawa 6- metoksi-7-oksigeranilkumarin [10]. Korelasi antara sinyal proton dengan sinyal karbon dalam dua atau tiga ikatan pada spektrum HMBC yang utama untuk mendukung struktur senyawa aurapten hasil isolasi dapat dilihat pada Tabel-4.

Tabel-1. Data spektrum NMR senyawa aurapten (1) dalam $\mathrm{CDCl}_{3}$

\begin{tabular}{|c|c|c|c|}
\hline No.C & $\delta_{\mathrm{H}}$ (multiplisitas) & $\boldsymbol{\delta}_{\mathrm{C}}$ & HMBC \\
\hline 2 & - & 161,4 & - \\
\hline 3 & $6,23(1 \mathrm{H}, d, J=9,6 \mathrm{~Hz})$ & 113,0 & $\mathrm{C}-2 ; \mathrm{C}-10$ \\
\hline 4 & $7,61(1 \mathrm{H}, d, J=9,6 \mathrm{~Hz})$ & 143,6 & C-2; C-5; C-6; C-8; C-9 \\
\hline 5 & $7,34(1 \mathrm{H}, d, J=8,6 \mathrm{~Hz})$ & 128,8 & C-4; C-6; C-7; C-9 \\
\hline 6 & $6,83(1 \mathrm{H}, d d, J=8,6 ; 2,4 \mathrm{~Hz})$ & 113,3 & C-7; C-8; C-10 \\
\hline 7 & - & 162,2 & - \\
\hline 8 & $6,80(1 \mathrm{H}, d, J=2,4 \mathrm{~Hz})$ & 101,7 & C-6; C-7; C-9 \\
\hline 9 & - & 155,9 & - \\
\hline 10 & - & 112,5 & - \\
\hline 1 ' & $4,58(2 \mathrm{H}, d, J=6,5 \mathrm{~Hz})$ & 65,6 & C-7; C-2'; C-3' \\
\hline 2 ' & $5,45(1 \mathrm{H}, t, J=6,6 \mathrm{~Hz})$ & 118,5 & C-1'; C-4'; C-10' \\
\hline $3^{\prime}$ & - & 142,5 & - \\
\hline 4 ' & $2,10(2 \mathrm{H}, m)$ & 39,6 & $\mathrm{C}-2^{\prime} ; \mathrm{C}-6^{\prime} ; \mathrm{C}-10^{\prime}$ \\
\hline 5 , & $2,12(2 \mathrm{H}, m)$ & 26,3 & $\mathrm{C}-3^{\prime} ; \mathrm{C}-4^{\prime}$ \\
\hline 6 ' & $5,06(1 \mathrm{H}, t, J=6,6 \mathrm{~Hz})$ & 123,7 & C-8'; C-9' \\
\hline 7 & - & 132,1 & - \\
\hline 8 & $1,59(3 \mathrm{H}, s)$ & 17,8 & C-6’; C-7'; C-9' \\
\hline 9' & $1,65(3 \mathrm{H}, s)$ & 25,8 & C-6'; C-7'; C-8' \\
\hline $10^{\prime}$ & $1,75(3 \mathrm{H}, s)$ & 16,9 & C-2'; C-3'; C-4' \\
\hline
\end{tabular}

Tabel-2. Data spektrum NMR senyawa 7-(2'E,6'E)-5'-hidroksi-3',7'-dimetilokta-2',6'-dieniloksi) kumarin (2) dalam $\mathrm{CDCl}_{3}$

\begin{tabular}{|c|c|c|c|}
\hline No.C & $\delta_{\mathrm{H}}($ multiplisitas $)$ & $\delta_{\mathrm{C}}$ & HМBC \\
\hline 2 & - & 161,3 & - \\
\hline 3 & $6,23(1 \mathrm{H}, d, J=9,5 \mathrm{~Hz})$ & 113,0 & $\mathrm{C}-2 ; \mathrm{C}-10$ \\
\hline 4 & $7,62(1 \mathrm{H}, d, J=9,5 \mathrm{~Hz})$ & 143,4 & C-2; C-5, C-9 \\
\hline 5 & $7,35(1 \mathrm{H}, d, J=8,6 \mathrm{~Hz})$ & 128,7 & C-4; C-7; C-9 \\
\hline 6 & $6,82(1 \mathrm{H}, d d, J=8,6 ; 2,4 \mathrm{~Hz})$ & 113,1 & C-8; C-10 \\
\hline 7 & - & 161,9 & - \\
\hline 8 & $6,79(1 \mathrm{H}, d, J=2,4 \mathrm{~Hz})$ & 101,4 & $\mathrm{C}-7 ; \mathrm{C}-9$ \\
\hline 9 & - & 155,8 & - \\
\hline 10 & - & 112,5 & - \\
\hline 1 ' & $4,59(2 \mathrm{H}, d, J=6,5 \mathrm{~Hz})$ & 65,1 & C-7; C-2'; C-3' \\
\hline 2 ' & $5,55(1 \mathrm{H}, t, J=6,5 \mathrm{~Hz})$ & 121,7 & $\mathrm{C}-4^{\prime}, \mathrm{C}-10^{\prime}$ \\
\hline 3 & - & 138,9 & - \\
\hline 4 ' & $2,25(2 \mathrm{H}, m)$ & 47,7 & C-2'; C-3', C-5'; C-6'; C-10' \\
\hline 5 & $4,51(1 \mathrm{H}, m)$ & 66,3 & $\mathrm{C}-7$ \\
\hline 6 ' & $5,16(1 \mathrm{H}, d, J=8,6 \mathrm{~Hz})$ & 127,2 & C-4', C-10' \\
\hline $7^{\prime}$ & - & 135,5 & - \\
\hline 8 & $1,69(3 \mathrm{H}, s)$ & 25,7 & C-6’; C-7’; C-9' \\
\hline $9^{\prime}$ & $1,67(3 \mathrm{H}, s)$ & 18,2 & C-6'; C-7'; C-8' \\
\hline $10^{\prime}$ & $1,80(3 \mathrm{H}, s)$ & 17,0 & C-2’; C-3’, C-5’ \\
\hline
\end{tabular}


Tabel-3. Data spektrum NMR senyawa 7-(2'E,5'E)-7'-hidroksi -3',7'-dimetilokta-2',5'-dieniloksi) kumarin (3) dalam $\mathrm{CDCl}_{3}$

\begin{tabular}{|c|c|c|c|}
\hline No.C & $\delta_{\mathrm{H}}$ (multiplisitas) & $\boldsymbol{\delta}_{\mathrm{C}}$ & HMBC \\
\hline 2 & ii 1 & 161,3 & - \\
\hline 3 & $6,24(1 \mathrm{H}, d, J=9,4 \mathrm{~Hz})$ & 113,0 & C-2; C-5; C-9 \\
\hline 4 & $7,63(1 \mathrm{H}, d, J=9,4 \mathrm{~Hz})$ & 143,5 & $\mathrm{C}-2 ; \mathrm{C}-10$ \\
\hline 5 & $7,36(1 \mathrm{H}, d, J=8,6 \mathrm{~Hz})$ & 128,7 & C-4; C-7; C-9 \\
\hline 6 & $6,85(1 \mathrm{H}, d d, J=8,6 ; 2,4 \mathrm{~Hz})$ & 113,2 & C-8; C-10 \\
\hline 7 & - & 162,0 & - \\
\hline 8 & $6,81(1 \mathrm{H}, d, J=2,4 \mathrm{~Hz})$ & 101,5 & C-6; C-7; C-9 \\
\hline 9 & - & 155,8 & - \\
\hline 10 & - & 112,4 & - \\
\hline 1 ' & $4,59(2 \mathrm{H}, d, J=6,6 \mathrm{~Hz})$ & 65,4 & C-7; C-2'; C-3' \\
\hline 2 ' & $5,49(1 \mathrm{H}, t, J=6,6 \mathrm{~Hz})$ & 119,2 & C-4', C-10' \\
\hline 3 ' & - & 141,1 & - \\
\hline 4 ' & $2,78(2 \mathrm{H}, d, J=6,1 \mathrm{~Hz})$ & 42,1 & C-2’; C-5’; C-6’; C-10’ \\
\hline 5 , & $5,61(1 \mathrm{H}, m)$ & 123,8 & C-4'; C-6'; C-8', C-9'; C-10' \\
\hline 6 ' & $5,68(1 \mathrm{H}, d, J=15,5 \mathrm{~Hz})$ & 140,4 & C-9', C-10' \\
\hline 7 ' & - & 70,7 & - \\
\hline 8 & $1,32(3 \mathrm{H}, s)$ & 29,8 & C-6'; C-7'; C-9' \\
\hline 9' & $1,32(3 \mathrm{H}, s)$ & 29,8 & C-6’; C-7’; C-8' \\
\hline $10^{\prime}$ & $1,74(3 \mathrm{H}, s)$ & 16,8 & C-2'; C-3', C-4' \\
\hline
\end{tabular}

Tabel-4. Data spektrum NMR senyawa 6-metoksi-7-oksigeranilkumarin (1) dalam $\mathrm{CDCl}_{3}$

\begin{tabular}{|c|c|c|c|}
\hline No.C & $\delta_{H}$ (multiplisitas) & $\boldsymbol{\delta}_{\mathrm{C}}$ & HMBC \\
\hline 2 & - & 161.6 & - \\
\hline 3 & $6,27(d, 9,5)$ & 113.3 & $\mathrm{C}-2 ; \mathrm{C}-10$ \\
\hline 4 & $7,62(d, 9,5)$ & 143.4 & C-2; C-5; C-9 \\
\hline 5 & $6,85(s)$ & 107.9 & C-7; C-10 \\
\hline 6 & - & 146.6 & - \\
\hline 7 & - & 152.0 & - \\
\hline 8 & $6,83(s)$ & 101.1 & C-6; C-10 \\
\hline 9 & - & 149.8 & - \\
\hline 10 & - & 111.2 & - \\
\hline $1 '$ & $4,69(d, 6,5)$ & 66.3 & $\mathrm{C}-7 ; \mathrm{C}-2^{\prime} ; \mathrm{C}-3^{\prime}$ \\
\hline 2 ' & $5,48(t, 5,3)$ & 118,3 & $\mathrm{C}-3^{\prime} ; \mathrm{C}-4^{\prime}$ \\
\hline $3^{\prime}$ & - & 142.1 & - \\
\hline $4^{\prime}$ & $2,08(m)$ & 39.5 & C-2'; C-5', C-6' \\
\hline 5, & $2,08(\mathrm{~m})$ & 26.1 & $\mathrm{C}-3^{\prime} ; \mathrm{C}-4^{\prime}, \mathrm{C}-7^{\prime}$ \\
\hline $6^{\prime}$ & $5,06(t, 5,3)$ & 123.6 & C-7'; C-10' \\
\hline 7 ' & - & 131.9 & - \\
\hline $8^{\prime}$ & $1,65(s)$ & 17.7 & C-6'; C-7'; C-9' \\
\hline 9' & $1,59(s)$ & 25.6 & C-6'; C-7'; C-8' \\
\hline $10^{\prime}$ & $1,77(s)$ & 16.8 & C-2'; C-3'; C-4' \\
\hline $6-\mathrm{OCH}_{3}$ & $3,91(s)$ & 56.3 & C-6 \\
\hline
\end{tabular}


Tabel-4. Data spektrum NMR senyawa 8-oksi-geranilpsoralen (5) dalam $\mathrm{CDCl}_{3}$

\begin{tabular}{|c|c|c|c|}
\hline No.C & $\delta_{\mathrm{H}}$ (multiplisitas) & $\boldsymbol{\delta}_{\mathrm{C}}$ & HMBC \\
\hline 2 & - & 160.7 & - \\
\hline 3 & $6,37(d, 9,6)$ & 114.8 & C-2; C-10 \\
\hline 4 & $7,77(d, 9,6)$ & 144.4 & C-2; C-5; C-9 \\
\hline 5 & $7,36(s)$ & 113.3 & C-4; C-7; C-3' \\
\hline 6 & - & 125.9 & - \\
\hline 7 & - & 148.8 & - \\
\hline 8 & - & 131.5 & - \\
\hline 9 & - & 143.3 & - \\
\hline 10 & - & 116.5 & - \\
\hline $1 '$ & - & - & - \\
\hline $2^{\prime}$ & $7,69(d, 2,2)$ & 146.4 & C-6; C-7 \\
\hline $3^{\prime}$ & $6,81(d, 2,2)$ & 106.8 & C-6; C-7, C-2; \\
\hline 1, & $5,03(d, 7,2)$ & 70,2 & $\mathrm{C}-8 ; \mathrm{C}-2{ }^{\prime}$; $\mathrm{C}-3$ ', \\
\hline 2, & $5,59(t, 7,2)$ & 119,5 & $\mathrm{C}-3^{\prime \prime} ; \mathrm{C}-4$, \\
\hline 3, & - & 143,3 & - \\
\hline $4 "$, & $2,00(m)$ & 39,7 & C-2"'; C-6"'; C-10"' \\
\hline 5, & $2,00(\mathrm{~m})$ & 26,4 & $\mathrm{C}-3{ }^{\prime \prime} ; \mathrm{C}-4$ ', \\
\hline $6 "$ & $5,02(t, 7,2)$ & 123,8 & C-8',' C-9', \\
\hline $7^{\prime \prime}$ & - & 131,8 & - \\
\hline 8, & $1,69(s)$ & 16,6 & C-6'; C-7'; C-9' \\
\hline $9^{\prime \prime}$ & $1,64(s)$ & 25,7 & C-6'; C-7'; C-8' \\
\hline 10, & $1,56(s)$ & 17,8 & C-2'; C-3'; C-4' \\
\hline
\end{tabular}

Tabel-5. Nilai $I_{50}$ senyawa kumarin ter-O-geranilasi hasil isolasi

\begin{tabular}{lc}
\multicolumn{1}{c}{ Senyawa } & IC $_{\mathbf{5 0}}(\boldsymbol{\mu} \mathbf{g} / \mathbf{m l})$ \\
\hline Aurapten (1) & 462 \\
7-(2'E,6' $E)$-5'-Hidroksi-3',7'-dimetilokta-2',6'-dieniloksi) kumarin (2) & 13 \\
7-(2'E,5' $E$ )-7'-Hidroksi-3',7'-dimetilokta-2',5'-dieniloksi) kumarin (3) & 260 \\
6-Metoksi-7-oksigeranilkumarin (4) & 210 \\
8-Oksi-geranilpsoralen (5) & 234 \\
Asam askobat & 58 \\
\hline
\end{tabular}

\section{8-Oksi-geranilpsoralen}

(5) berwujud padatan kuning muda. Spektrum ${ }^{1}$ H-NMR senyawa $\mathbf{5}$ memperlihatkan dua sinyal singlet proton aromatik pada $\delta_{\mathrm{H}} 6,85$ dan $6,83 \mathrm{ppm}$ dan sepasang sinyal doublet cis-vinilik $(J=$ $9,5 \mathrm{~Hz}$ ) pada $\delta_{\mathrm{H}} 7,62$ dan $6,27 \mathrm{ppm}$ yang khas untuk senyawa kumarin disubstitusi. Sinyal proton senyawa $\mathbf{5}$ memperlihatkan adanya sinyal proton geranil dan metoksi. Spektrum ${ }^{13} \mathrm{C}-\mathrm{NMR}$ senyawa $\mathbf{5}$ memperlihatkan 20 sinyal atom karbon yang terpisah secara sempurna. Spektrum HMBC (Tabel-4) memperlihatkan adanya korelasi antara sinyal proton metilen pada $\delta_{\mathrm{H}} 4,69(\mathrm{H}-1$ ') memperlihatkan korelasi dengan satu sinyal karbon oksiaril pada $\delta_{\mathrm{C}} 152.0$ (C-7), satu sinyal karbon metin pada $\delta_{\mathrm{C}} 118,3$ (C-2') dan satu sinyal karbon kuarterner pada $\delta_{\mathrm{C}} 142.1$ (C-3') yang menunjukkan $O$-geranil terikat di C7. Sinyal singlet proton aromatik pada $\delta_{\mathrm{H}}$ 6,83 (H-8) memperlihatkan korelasi dengan satu sinyal karbon oksiarin pada $\delta_{\mathrm{C}} 146.6$ (C-6) dan satu sinyal karbon kuarterner pada $\delta_{\mathrm{C}} \quad 111.2 \quad(\mathrm{C}-10)$ sedangkan sinyal proton metoksi berkorelasi dengan sinyal karbon oksiarin 
pada $\delta_{\mathrm{C}} 146.6$ (C-6). Analisis spektrum HMBC tersebut maka disimpulkan bahwa senyawa 5 adalah senyawa 6metoksi-8-oksi-geranilpsoralen [12].. Korelasi antara sinyal proton dengan sinyal karbon dalam dua atau tiga ikatan pada spektrum HMBC yang utama untuk mendukung struktur senyawa aurapten hasil isolasi dapat dilihat pada Tabel-4.

Uji aktivitas antioksidan senyawa 1-5 terhadap radikal DPPH memperlihatkan nilai konsentrasi daya hambat $\mathrm{IC}_{50}$ adalah $462 ; 13 ; 260 ; 210$ dan $234 \mu \mathrm{g} / \mathrm{ml}$. Senyawa 1-4 merupakan kumarin ter- $O$-geranilasi di C-7. Senyawa aurapten (1) substituen oksi 3,7-dimetil okta-2,6-diena memperlihatkan aktivitas antioksidan dengan yang paling lemah dengan nilai $\mathrm{IC}_{50}$ sebesar $462 \mu \mathrm{g} / \mathrm{ml}$ diantara semua senyawa kumarin ter- $O$ geranilasi di C-7. Adanya tambahan gugus metoksi di C-6 pada senyawa 6metoksi-7-oksigeranilkumarin

meningkatkan aktivitas antioksidan sebanyak dua kali yakni nilai $\mathrm{IC}_{50}$ sebesar $210 \mu \mathrm{g} / \mathrm{ml}$. Oksidasi rantai samping geranil pada senyawa $\mathbf{2 - 3}$ yang menghasilkan alilik alkohol memperlihatkan aktivitas antioksidan meningkat. Senyawa 2 dengan adanya tambahan gugus hidroksi di C-5, memperlihatkan nilai $\mathrm{IC}_{50}$ sebesar $13 \mu \mathrm{g} / \mathrm{ml}$ dan aktivitasnya 35 kali lebih kuat dibanding senyawa 1. Senyawa 3 merupakan isomer dari senyawa 2 mempunyai nilai $\mathrm{IC}_{50}$ sebesar $260 \mu \mathrm{g} / \mathrm{ml}$ memperlihatkan aktivitas antioksidan dua kali lebih kuat dibanding senyawa 1. Senyawa 5 memperlihatkan aktivitas antioksidan yang hampir sama dengan senyawa 3 dan 4 . Senyawa 2 memperihatkan aktivitas antioksidan yang sangat tinggi, empat kali lebih kuat dibandingkan asam askorbat. Nilai $\mathrm{IC}_{50}$ senyawa kumarin ter-O-geranilasi dari akar Limonia accidissima L. dapat dilihat pada Tabel-5.

\section{KESIMPULAN}

Lima senyawa kumarin ter- $O$ geranilasi yakni aurapten (1), 7(2' $\left.E, 6^{\prime} E\right)$-5' -hidroksi-3',7'-dimetilokta2',6'-dieniloksi)kumarin (2), 7-(2'E,5' $E)$ 7'- hidroksi -3', 7'- dimetilokta-2', 5'dieniloksi) kumarin (3), 6-metoksi-7oksigeranilkumarin (4), dan 8-oksigeranilpsoralen (5) telah diisolasi dari akar Limonia accidissima L. Senyawa 24 merupakan senyawa kumarin ter- $O$ geranilasi pertama diisolasi dari Limonia accidissima L. Senyawa 7-(2'E,6'E) -5'hidroksi-3', 7'-dimetilokta-2',6'-

dieniloksi)kumarin (2) mempunyai aktivitas antioksidan yang poten terhadap radikal DPPH.

\section{UCAPAN TERIMAKASIH}

Ucapan terimakasih disampaikan kepada Menristek Dikti melalui dana riset Penelitian Unggulan Perguruan Tinggi, PUPT, Universitas Airlangga tahun 2015.

\section{DAFTAR PUSTAKA}

[1]. Heyne, K., 1987. Tumbuhan Berguna Indonesia, Jilid II, Badan Penelitian dan Pengembangan Kehutanan, Departemen Kesehatan Republik Indonesia, Jakarta.

[2]. Tjahjandarie, T.S., Saputri, R.D., Tanjung, M., 2016. Oxygeranylated coumarins from the root of Limonia accidisima $\mathrm{L}$. and their DPPH radical scavenging activity. Der Pharmacia Lettre. 8: 33-36.

[3]. Tjahjandarie, T.S., Tanjung, M., 2015. Lead compound antimalaria dan antioksidan senyawa alkaloid, flavonoid, dan kumarin dari Limonia accidisima L.. Laporan Akhir Penelitian Unggulan Perguruan Tinggi, Universitas Airlangga. $1-45$.

[4]. Tanjung, M., Tjahjandarie, T.S., Sentosa, M.H., 2013. Antioxidant and cytotoxic agent from the rhizomes of Kaempferia pandurata. Asian Pacific J. Tropical Disease. 3(5): 401-404.

[5]. Tanjung, M., Saputri, R.D., Tjahjandarie, T.S., 2014. Antioxidant activity of two isomeric benzoxepin derivatives from the stem bark of Bauhinia aculeata L. J. Chem. Pharm. Res. 6: 705-708. 
[6]. Tjahjandarie, T.S., Pudjiastuti, P., Saputri, R.D., Tanjung, M., 2014. Antimalaria and antioxidant activity of phenolic compounds isolated from Erythrina crystagalli L. J. Chem. Pharm. Res. 6: 786-790.

[7]. Marliana, E., Tjahjandarie, T.S., Tanjung, M., 2016. Aktivitas antioksidan senyawa flavonoid dari Macaranga pearsonii Merr. J. Kimia Mulawarman. 13(2): 97-100.

[8]. Noorhajati, H., Tanjung, M., Aminah, N.S., Suwandi, J.S.A. 2012. Antioxidant activities of extracts of trengguli stem bark (Cassia fistula L.), Int $\mathbf{J}$ Basic Appl.Sci. 12: 85-89.

[9]. Tanjung, M., Saputri, R.D., Tjahjandarie, T.S., 2016. 5,9,11-Trihydroxy-2,2dimethyl-10-(3'-methyl-2'-butenyl)-3(2"-methyl-3"-butenyl)pyrano[2,3a]xanthen-12(2H)-one from the stem bark of Calophyllum pseudomole. Molbank. M906. 3: 1-5.
[10]. Chen, I-S., Lin, Y-C,. Tsai, I-L,. Teng, CM,. Ko, F-N., Ishikawa, T,. Ishii, H. 1995. Coumarins and anti-platelet aggregation constituents from Zanthoxylum schinifolium. Phytochem.39(5): 10911097.

[11]. Chang, C-T., Doong, S-L,. Tsai, I-L,. Chen, I-S., 1997. Coumarins and anti-HBV from Zanthoxylum schinifolium. Phytochem.45(7): 1419-1422.

[12]. Nguyen, P-H,. Zhao, B.T,. Kim, Okhwa,. Lee, J.H,. Choi, J.S,. Min, B.S,. Woo, M.H, $\quad 2016 . \quad$ Anti-inflammatory terpenylated coumarins from the leaves of Zanthoxylum schinifolium with $\alpha$ glucosidase inhibitory activity. J. Nat. Med. 70: 276-281.

How to cited this article :

Tjahjandarie TS, Saputri RD, Tanjung M. 2017. Aktivitas Antioksidan Senyawa Kumarin Ter-o-geranilasi dari Akar Limonia acidissima L. J. Trop.Pharm. Chem. 2017; (4)2; p.79-87 